\title{
RESENHA
}

\section{O público da Teologia Pública: a contribuição de Paul Tillich}

\author{
Alonso S. Gonçalves*
}

CUNHA, Carlos. Paul Tillich e a teologia pública no Brasil: o contributo do método da correlação de Paul Tillich à epistemologia da teologia pública no Brasil no contexto do pensamento complexo e transdisciplinar. São Paulo: Garimpo, 2016, 408p.

A teologia, enquanto discurso teológico, tem por vocação interagir com a sociedade. Nesse sentido ela, per si, tem um caráter público. A teologia pública, desenvolvida por alguns autores, quer ser mediadora de metodologias e linguagens que possibilitem comunicação e ação no espaço público. Para isso, a teologia necessita dialogar com o seu contexto de forma a interagir com as questões relevantes da sociedade. Essa tarefa se constitui a partir de conflitos, principalmente quando teologia é entendida como pertencente à igreja, sendo ensinada em faculdades e seminários confessionais como uma doutrinação para defender a fé de ameaças, pretensamente, heréticas. Nesse sentido, uma das maiores dificuldades para se pensar uma teologia que seja pública, é a sua dependência de confissões de fé, com uma abordagem estritamente eclesial, no sentido de produzir teologia para dentro da comunidade de fé e nunca, com raras exceções, para fora. Pensar teologia fora dos muros institucionais é um caminho difícil, pois compreende-se que teologia é para os cristãos e não, necessariamente, para a sociedade.

Longe de ser uma moradora dos seminários, faculdades confessionais e igrejas, a teologia quer ser uma leitura viável para o espaço público, daí a sua adjetivação teologia pública. Por ter conquistado legitimidade acadêmica recentemente (1999), ela se assenta nas ca-

Doutorando em Ciências da Religião (UMESP); Licenciatura em Filosofia (ICSH);

E-mail: alonso3134@hotmail.com 
deiras das ciências humanas procurando seu espaço epistemológico entre as majoritárias da sua área de conhecimento. Nesse sentido, a proposta de Carlos Cunha é bem vinda com o texto "Paul Tillich e a Teologia Pública no Brasil". Fruto de sua tese de Doutorado em Teologia pela Faculdade Jesuíta de Filosofia e Teologia - FAJE (Belo Horizonte/MG), o texto está dividido em três partes: 1 - O pensamento complexo-transdisciplinar; 2 - A teologia de fronteira de Paul Tillich; 3 - Teologia pública: encontros e diálogos.

$\mathrm{Na}$ primeira parte da pesquisa, o autor se dedica a demonstrar a plausibilidade da teologia no atual momento de mudanças paradigmáticas. Essas mudanças, segundo o autor, é consequência de um "tempo de crise". A "crise é proveniente da desorientação das sociedades que questionam os modelos adquiridos". Essa desorientação gerou insegurança e fez emergir novos modelos para a leitura da realidade. A crise se dá na sociedade, quando "sem mais a inocência de antes, as grandes questões pelo sentido da vida suscitam as mais agudas e perturbadoras inquietações". O autor assume o termo, controvertido, de pós-modernidade por entender que esse período "nega o otimismo intelectual da modernidade". Para o autor há uma crise na religião. Embora considere como um aspecto complexo de determinação, ele concebe um tempo de indefinição por ser favorável a possibilidade de "diagnósticos díspares sobre o futuro ou não da religião". Para fechar a sua tríplice concepção de crise, o autor elenca o conhecimento que vem sofrendo mudanças de perspectivas, principalmente o "descompasso entre o conhecer e o viver". Essa crise gerou a crise de paradigmas, ocasionando novos modelos como o pensamento complexo, que tem em Edgar Morin um dos principais teóricos. Com a teoria da complexidade, o autor tem o seu aporte teórico para conceber um tempo onde tudo está interligado e a metáfora que expressa essa ideia é a rede. Por isso que a transdisciplinaridade é um paradigma que se sustenta por não conceber mais separações e compartimentos isolados do conhecimento. A leitura do mundo, e sua dinamicidade, exige múltiplos olhares e uma lógica clássica não tem mais espaço, surgindo então uma lógica do terceiro termo incluído, ou seja, superando a visão aristotélica. Dessa maneira, há condição para que "uma epistemologia que carrega no seu bojo o pensamento complexo e transdisciplinar" se sustente. É dentro 
desse aspecto do conhecimento que o autor justifica o lugar da teologia quando interpelada pela realidade, tendo, portanto, a possibilidade de contribuir com sua linguagem e discurso.

$\mathrm{Na}$ segunda parte do texto, o autor se dedica a expor o pensamento teológico de Paul Tillich, o autor-referência do seu trabalho. Com Tillich, o autor quer legitimar o que discutiu na primeira parte (O pensamento complexo-transdisciplinar), elegendo o método tillichiano da correlação como um caminho para se pensar teologia no espaço público. Por ser conhecido como um teólogo da fronteira, Tillich concatena o conhecimento em sua diversidade (filosofia, teologia e ciência), o que dá ao autor do nosso trabalho condições para formular uma "teologia que-dá-respostas" diante das questões da contemporaneidade. Tillich, um extemporâneo, desenvolveu uma linguagem teológica para o seu tempo e o autor explora isso a partir das publicações do teólogo alemão-estadunidense, bem como o seu método da correlação. Apropriando-se do método tillichiano, o autor coloca o teólogo em condições de dialogar com as questões da existência humana, dando, assim, meios para o próximo passo do seu trabalho, uma teologia que tenha o que dizer quando legitimada no espaço público.

A terceira parte é, propriamente, a tese do autor. A sua principal pergunta é: como a teologia pode se articular em um tempo marcado por mudanças estruturais, onde as transformações são dinâmicas e as respostas são plurais? Atento a este tempo, o autor sentencia: "urge a necessidade de reconstrução de uma epistemologia teológica capaz de dialogar com o mundo atual". Em busca dessa epistemologia teológica, é necessário abertura "à complexidade da vida e ao diálogo transdisciplinar, que se articula a partir das diferentes relações". Para o que propõe, o autor enfrenta o primeiro problema: colocar a teologia na praça pública. Sua argumentação passa pela leitura bíblica, demonstrando a publicidade da teologia; pela conceituação de teologia públi$c a$, conduzida pela complexidade-transdisciplinar, como também pelo pensamento de Tillich. Assim, surge uma teologia com consciência, ou seja, uma teologia aberta às demandas da sociedade, da universidade e da igreja. Dessa maneira, a principal tarefa da teologia pública é desenvolver um discurso que contemple as diferentes confissões de fé; que participe dos setores sociais; que tenha uma linguagem inclusiva; que 
dialogue com outras ideias; que interprete o momento atual com uma hermenêutica bíblica, tendo a vida como mediação. Para esse esforço tornar-se em práxis, o autor ilumina o caminho: "a teologia pública é um serviço prestado pelas comunidades de fé ao mundo. Ela exerce uma função mediadora entre as pessoas cristãs e a sociedade [...] em diálogo direto com diferentes órgãos governamentais, na participação junto à sociedade civil, através de movimentos sociais e na contribuição para a formação cidadã". O público da teologia, quando aberta ao diálogo e com legitimidade epistemológica, política e cultural, se dá pelo inacabamento - "teologias inacabadas e caminhantes são teologias abertas, isto é, abertas a encontros alimentados por diálogos com a cultura"; pela criatividade - a capacidade "de se refazer de maneira nova e relevante diante da sociedade".

Algumas considerações são possíveis a partir deste trabalho.

A teologia pública procura o seu lugar. Quando o autor coloca Paul Tillich como ponto preponderante no texto, esperava-se não apenas a dedicação ao seu método (correlação) e sua principal característica (fronteira), mas também a sua teologia da cultura, mencionada pelo autor mas não explorada. A teologia da cultura é mais apelativa para uma linguagem pública da teologia, uma vez que Tillich analisa a cultura a partir de símbolos, permitindo assim um discurso teológico inteligível onde temas como Jesus Cristo, salvação e igreja, ganham novos contornos. Além da teologia da cultura, o autor não olhou com mais cuidado para a concepção de fé em Tillich. A fé não pode ser tomada como um conhecimento. A sua legitimidade é inata como bem define Tillich - "é estar possuído por aquilo que nos toca incondicionalmente". Sendo algo intrínseco ao ser humano, como uma dimensão primeira deste, a fé se constitui em uma realidade que envolve o ser humano e todas as suas características e não apenas uma parte ou função, se é que é possível dividi-lo.

A construção da linguagem da teologia pública é tomada a partir de algumas noções do que seja o espaço público para ser interlocutora (sociedade, universidade e igreja). Essa demanda se torna em desafio no Brasil por ser a teologia restrita às confissões de fé onde a marca preponderante do saber é a revelação. 
Uma teologia pública que tem na revelação o seu principal ponto de abertura para o espaço público, onde entende-se que "na busca sincera pelo conhecimento, o sujeito atinge algo de absoluto e o absoluto é Deus", tem dificuldades em dialogar com a ciência. Se a base epistemológica da teologia que quer ser pública é a complexidade-transdisciplinaridade, não poderá entender teologia com base na revelação e escrituras de maneira lato sensu. Uma vez que as escrituras também é linguagem e também é concebida a partir de uma cultura. Em outro lugar o autor concebe uma hermenêutica da revelação - "falar sobre Deus é a tarefa primeira do teólogo. É evidente que o objeto da teologia não é ele em absoluto, mas falar dele". Aqui, portanto, a revelação não é tomada como um conhecimento absoluto, mas como linguagem que tem na hermenêutica a sua mediação, sendo assim, "como disciplina humana, ela é ciência hermenêutica, mediada pela realidade, sujeita às limitações da intelecção e dicção próprias da condição humana". Caberia, portanto, uma distinção no papel da teologia pública na esfera social e acadêmica. Na primeira, a tarefa da teologia pública se dá a partir da experiência da fé; quanto à segunda, o principal elemento seria a hermenêutica, propondo interpretações a partir de bases comuns ao conhecimento científico, e não tendo, necessariamente, a revelação como ponto de partida.

A contribuição do teólogo Carlos Cunha nesse trabalho é salutar. O seu texto recebeu "Menção Honrosa" da CAPES pela proposta apresentada. Merecidamente. Para todo o autor, o maior benefício que seu trabalho pode receber é a reverberação daquilo que teve a capacidade intelectual de propor. Por isso, recomendamos a leitura desse livro a fim de ampliar o debate em torno do tema teologia e espaço público. 